\title{
ANÁLISE DO TRANSPORTE DAS EMISSÕES DE MONÓXIDO DE CARBONO (CO) NO ESTADO DO PARÁ
}

\author{
PAIXÃO, Lúcia Cardoso - ambientelucia@gmail.com \\ Universidade Federal do Pará / UFPA \\ CATTANIO, José Henrique - cattanio@ufpa.br \\ Universidade Federal do Pará / UFPA \\ KUHN, Paulo - pkunh@ufpa.br \\ Universidade Federal do Pará / UFPA
}

\begin{abstract}
RESUMO: Entender o comportamento das emissões atmosféricas de gases como o monóxido de carbono (CO), é extremamente importante para uma eficiente gestão ambiental no Estado do Pará. A estação seca de 2010 foi caracterizada por baixas taxas de precipitação pluviométrica, especialmente em agosto e setembro quando foram registradas os menores volumes de chuva. Durante este período, inúmeros focos de incêndios, decorrentes do processo de queima da biomassa vegetal da região, foram identificados, cuja quantidade aumentou à medida em que a seca se intensificou. Diante desse cenário, a pesquisa realizada teve como objetivo estudar a concentração, transporte e a dispersão das emissões de monóxido de carbono (CO), provenientes não só da queima da biomassa vegetal, mas também das atividades industriais existentes no Estado, durante o período seco de 2010, nos meses de junho, julho, agosto, setembro, outubro e novembro e correlacionar estas emissões com o modelo de desenvolvimento econômico adotado no Estado do Pará. Para este estudo utilizou-se o modelo numérico CATT-BRAMS (Coupled Aerosol and Tracers Transport Model to the Brazilian Regional Atmospheric Modelling System) na versão 4.2 do BRAMS (FREITAS et al., 2009) com dados de inicialização provenientes do modelo global AVN/NCEP (Aviation run of the National Centers for Environmental Prediction Global Spectral Model) e assimilação dos dados de fogo (focos de queimadas e emissões antropogênicas) derivados por sensoriamento remoto. As simulações de CO realizadas com o CATT-BRAMS que as emissões deste poluente, após serem enviadas para a atmosfera, foram submetidas às ações dos ventos horizontais e ao processo de turbulência vertical (condições de convecção local), atingindo outras regiões e altos níveis de altitude, abrangendo assim dimensões continentais. As simulações destacaram também as mesorregiões Nordeste, Sudeste e Sudoeste, no Estado do Pará, com as maiores concentrações de CO, acarretando deterioração da qualidade do ar local, chegando a ultrapassar os padrões legais permitidos pela legislação ambiental brasileira, durante todo o período estudado. $O$ perfil econômico do Estado, basicamente extrativista, com predominância dos setores agropecuário e florestal, que se caracterizam pelo desmatamento e queima da biomassa vegetal, bem como as atividades industriais, com o uso de combustíveis fósseis em seus processos produtivos, explicaram, em parte, a qualidade do ar das mesorregiões destacadas. Outra característica importante, que também possui forte responsabilidade na dispersão do $\mathrm{CO}$, é o relevo do Estado, com predominância de terrenos com cotas topográficas modestas, e uma extensa planície sedimentar. Isto possibilitou uma significativa movimentação de poluentes atmosféricos vindos de outros Estados, e da entrada de massa de ar do oceano para o continente, trazendo elevadas concentrações de poluentes para a região e transportando-os para o oeste.
\end{abstract}

Palavras-chave: Monóxido de Carbono (CO), Transporte atmosférico, Dispersão, Modelo Numérico CATT-BRAMS 


\section{ANALYSIS OF TRANSPORTATION OF EMISSIONS OF CARBON MONOXIDE (CO) IN THE} STATE OF PARÁ

ABSTRACT: Understanding the behavior of atmospheric emissions of gases, such as carbon monoxide (CO), is extremely important for an effective environmental management in the state of Pará. The 2010 dry season was characterized by low rainfall rates, especially in August and September which presented the lowest rainfall. During this period, numerous of fires focus, resulting from the process of burning the vegetable biomass of the region, were identified, the amount of which increased as the drought intensified. In this scenario, the objective of this research was to study the concentration, transport and dispersion of carbon monoxide (CO) emissions, not only from the burning of vegetable biomass, but also from industrial activities in the State during the dry period of the 2010 year, in the months of June, July, August, September, October and November and to correlate these emissions with the model of economic development adopted in the state of Pará. In this study, was used the CATT-BRAMS model (Coupled Aerosol and Tracers Transport Model to the Brazilian Regional Atmospheric Modeling System) in version 4.2 of BRAMS (Freitas et al., 2009), with initialization datas from the global AVN / NCEP (Aviation run of the National Centers for Environmental Prediction Global Spectral Model) and assimilation of fires datas (fires and anthropogenic emissions) derived by remote sensing. The $\mathrm{CO}$ simulations showed that the emissions of this pollutant, after being sent to the atmosphere, were submitted to the actions of the horizontal winds and to the vertical turbulence process (local convection conditions), reaching other regions and high-altitude levels, thus covering continental dimensions. The simulations also highlighted the Northeast, Southeast and Southwest mesoregions in the state of Pará with the highest concentrations of $\mathrm{CO}$, causing a deterioration of local air quality, even exceeding the legal standards allowed by Brazilian environmental legislation, throughout the studied period. The economic profile of the State, basically extractive, with predominance of the agricultural and forestry sectors, which are characterized by the deforestation and burning of the vegetal biomass, as well as the industrial activities, with the use of fossil fuels in their productive processes, explained in part the quality of the air in the highlighted mesoregions. Another important aspect, which also has a strong responsibility for the dispersion of $\mathrm{CO}$, is the State's relief, with a predominance of terrains with modest topographic dimensions, and an extensive sedimentary plain. This allowed a significant movement of atmospheric pollutants from other States, and the influx of air from the ocean to the mainland, bringing high concentrations of pollutants to the region and transporting them to the west.

Keywords: Carbon Monoxide (CO), Atmospheric Transport, Dispersion, Numerical Model CATT-BRAMS.

\section{INTRODUÇÃO}

A Amazônia brasileira desempenha um papel fundamental no equilíbrio ambiental regional e global (GASH et al., 2004). Em sua extensa área de floresta tropical, com uma megabiodiversidade e abundância de recursos hídricos, operam processos de vida complexos, com um expressivo número de seres funcionando como engrenagens articuladas em uma fenomenal máquina de regulação ambiental (MARENGO et al., 2008). Porém, nas últimas décadas, ameaçadas pelo intenso processo de ocupação humana, o desmatamento já converteu quase $20 \%$ da extensão original das florestas pertencentes à Amazônia brasileira em pastagens ou terras agrícolas (ALMEIDA et al., 2016; BARBER et al., 2014). Dentro deste contexto, o Estado do Pará representa $26 \%$ de toda a extensão da região Amazônica (IBGE, 2010), sendo que entre os anos de 2008 e 2009, o Pará respondeu por 57\% do desmatamento total ocorrido na Amazônia Legal (INPE, 2016). As principais causas desse cenário estão relacionadas ao modelo tradicional de ocupação e de desenvolvimento predominantemente extrativista adotado no Pará, focado principalmente na 
agricultura familiar e aos grandes projetos agropecuários, destacando a cultura da soja e a pecuária extensiva (ALMEIDA et al., 2016).

As emissões de monóxido de carbono ( $\mathrm{CO}$ ) associadas à queima de biomassa na floresta natural na Amazônia são estimadas em $50.3 \pm 17.1 \mathrm{~g}$ de CO kg-1 de biomassa seca queimada (SOARES NETO et al., 2011). Foram encontradas fortes evidências de que o CO na atmosfera de parte da Bacia Amazônica, com concentrações maiores do que 300 ppbv, vem da queima da biomassa da floresta (ANDREAE et al., 2012). O interesse no ciclo atmosférico do $\mathrm{CO}$ é motivado pelo seu papel central na química atmosférica como um produto da foto-oxidação do metano $(\mathrm{CH} 4)$ e outros Carbonos Orgânicos Voláteis (COVs), como sumidouro dominante para o radical $\mathrm{OH}$, e como um precursor do ozônio troposférico (O3) (LOGAN et al., 1981).

No setor industrial merece destaque, principalmente, a indústria florestal (incluindo as carvoarias), que sendo responsável por elevar o Pará ao patamar de maior produtor de madeira da região Norte (40\% da produção regional), deixa, em seu desenvolvimento, a degradação de extensas áreas de floresta, pois a maioria da exploração madeireira ocorre de forma predatória, não manejada (VERÍSSIMO et al., 2002). Importantes estudos científicos já comprovaram os efeitos nocivos que as emissões provenientes da queima da biomassa vegetal e do setor industrial, compostas por uma mistura complexa de gases primários tóxicos e/ou precursores de gases secundários e de diversos tipos de aerossóis, provocam ao meio ambiente e à saúde humana. Dentre esses estudos merecem destaques Freitas et al. (2009), Guenther et al. (1995), Andreae; Crutzen (1997), Kaufman et al. (1998), Andreae et al. (2002), que demonstraram os efeitos danosos dessas emissões nos processos de microfísica e dinâmica de formação de nuvens, na composição e nas propriedades físicas e químicas da atmosfera, com significativo potencial de impacto ambiental, que podem atingir em uma escala local, regional e até global. Na saúde humana, estudos científicos comprovaram o potencial dessas emissões de induzir consideráveis distúrbios respiratórios, alergias, lesões degenerativas no sistema nervoso e em outros órgãos vitais do ser humano (ALVES et al., 2015; ARTAXO et al., 2005; CRUTZEN et al., 1979; FREITAS et al., 2005, 2009; GALVÃO et al., 2018; WEICHENTHAL et al., 2017).

Este trabalho tem como objetivo analisar a concentração, o transporte e a dispersão das emissões de $\mathrm{CO}$, provenientes da queima de biomassa vegetal e das atividades industriais existentes no Estado do Pará, durante os meses de junho, julho, agosto, setembro, outubro e novembro, no período seco do ano de 2010, utilizando-se o modelo numérico CATT-BRAMS (Coupled Aerosol and Tracers Transport Model to the Brazilian Regional Atmospheric Modelling System) na versão 4.2 do BRAMS, além de correlacionar estas emissões com o modelo de desenvolvimento econômico adotado no Pará. Atualmente o CATTBRAMS é bastante utilizado pelos meteorologistas, gestores ambientais e pesquisadores em estudos e em operações meteorológicas diárias. Como exemplo, Gevaerd et al. (2006) analisaram o transporte atmosférico de CO liberado pela queima de biomassa em Roraima, durante os três primeiros meses de 1998, enfatizando o papel dos sistemas convectivos profundos na redistribuição tridimensional da pluma de gás, utilizando o modelo CATT-BRAMS para as simulações numéricas; Freitas et al. (2006) utilizaram o CATT-BRAMS para simular a estação seca de 2002 ocorrida na América do Sul, durante as campanhas de campo do Smoke, Aerosols, Clouds, Rainfall (SMOCC) e Climate 
and Radiation, Cloud, and Climate Interactions in the Amazonia (RaCCI), projetos do LBA realizados na fase de transição da estação seca para a chuvosa e Ramos et al. (2009), diagnosticaram os campos de concentração e o transporte dos poluentes provenientes do incêndio florestal na região amazônica, ocorrido nas áreas do avanço da fronteira agrícola e em terreno de topografia variável. Optou-se por estudar o ano de 2010, em função da disponibilidade dos dados necessários aos estudos, existentes no laboratório de Modelagem Amazônica do Instituto de Geociências da Universidade Federal do Pará (UFPA) e por este ano ter apresentado um comportamento associado ao efeito de El Niño, que é um fenômeno climático, de caráter atmosféricooceânico, em que ocorre o aquecimento fora do normal das águas superficiais e subsuperficiais do Oceano Pacífico Equatorial, podendo alterar fatores climatológicos regionais do Pará, como a precipitação pluviométrica, e até mesmo fatores globais.

\section{MATERIAL E MÉTODOS}

O Pará encontra-se compreendido entre os paralelos $2^{\circ} \mathrm{N}$ e $5^{\circ} \mathrm{S}$ e os meridianos $56^{\circ} \mathrm{W}$ e $48^{\circ} \mathrm{W}$ (Figura 1a). É dividido em 5 mesorregiões: Baixo Amazonas; Marajó; Região Metropolitana de Belém; Nordeste; Sudeste; e, por último, Sudoeste Paraense, as quais serão utilizadas para a descrição dos resultados desse trabalho (Figura 1 b). O Estado possui clima quente e úmido e apresenta características climáticas diversificadas, decorrentes da combinação de vários fatores, destacando-se, dentre eles, a disponibilidade de energia solar através do balanço de energia (MORAES et al., 2005). A climatologia é caraterizada por pequena variação sazonal, com temperaturas médias acima de $250 \mathrm{C}$, em todos os meses do ano; umidade relativa do ar elevada, com valores médios acima de $80 \%$, índice pluviométrico anual atingindo valores de até 3300 $\mathrm{mm}$, trimestre mais chuvoso abrangendo os meses de março, abril, maio (MAM) seguidos de dezembro, janeiro e fevereiro (DJF), e os menos chuvosos: setembro, outubro, novembro (SON), seguidos de junho, julho e agosto (JJA) (ALBUQUERQUE; SOUZA, 2008; MORAES et al., 2005).

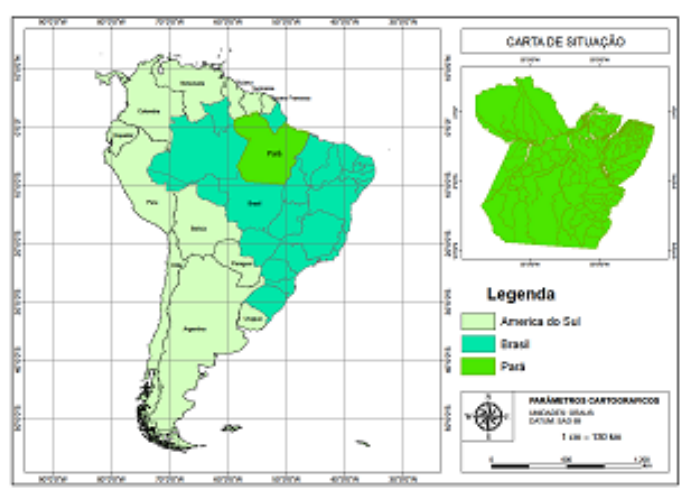

(a)

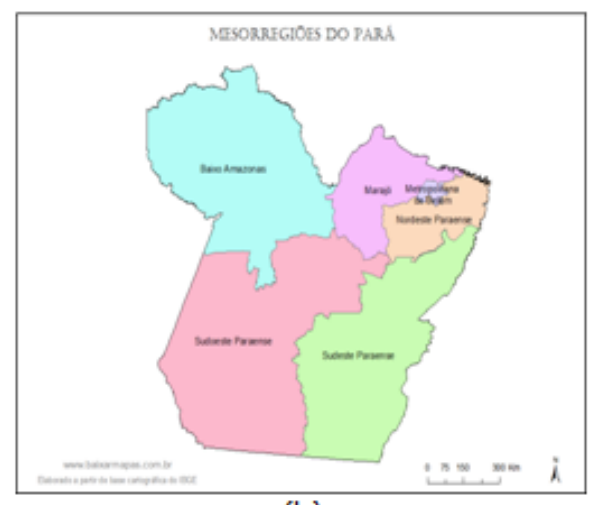

(b)

Figura 1- a) Mapa do Estado do Pará com destaque para a sua posição geográfica na América do Sul e no Brasil; b) a divisão do estado do Pará em seis mesorregiões. Fonte: Adaptado de Cartografia digital - www.baixarmapas.com.br 
Para visualizar o campo de concentração, o transporte atmosférico e a evolução (abrangência) da pluma de emissões de monóxido de carbono (CO) utilizou-se o modelo numérico CATT-BRAMS (Coupled Aerosol and Tracers Transport Model to the Brazilian Regional Atmospheric Modelling System), em sua versão 4.2 do BRAMS (FREITAS et al. , 2009), disponibilizada pelo Laboratório de Modelagem Amazônica da UFPA. O CATT-BRAMS é um modelo de transporte on line, em 3D, euleriano estabilizado, que prognostica a concentração de contaminantes atmosféricos de forma simultânea e completamente consistente com a dinâmica atmosférica, as quais foram simuladas pelos modelos RAMS e BRAMS em suas versões 6 e 4.2, respectivamente (FREITAS et al., 2007).

Deste modo, obtém-se o prognóstico simultâneo do Estado atmosférico, do ponto de vista meteorológico e da qualidade do ar, e o estudo da interação ou da retroalimentação entre o contaminante e a própria atmosfera (como no caso dos aerossóis liberados em incêndios e de seu forçamento radiativo) (FREITAS et al., 2009). Dados de uma descrição pormenorizada das parametrizações e as novas funcionalidades podem ser encontrados nos principais artigos que trabalharam com este modelo (ALONSO et al., 2010; FREITAS et al., 2015, 2005, 2009, 2012; GÁCITA et al., 2007).

O modelo numérico CATT-BRAMS foi inicializado e ajustado com as análises (condições iniciais e de contorno) do modelo global AVN/NCEP (Aviation run of the National Centers for Environmental Prediction Global Spectral Model) com assimilação dos dados de fogo (focos de calor provenientes das queimadas e das emissões antropogênicas que ocorrem na regi) derivados por sensoriamento remoto (MODIS Moderate-Resolution Imaging Spectroradiometer) e AVHRR (Advanced Very High Resolution Radiometer) abordo dos satélites polares AQUA e TERRA, juntamente com imagens dos satélites geoestacionários GOES e MSG, abordo da série de satélites de órbita polar NOAA, disponibilizados pelo CPTEC/INPE, para o Estado do Pará.

A simulação foi inicializada às 00:00 UTC do dia 01 de junho até às 00:00 UTC de 01 de dezembro de 2010, correspondente ao período seco, ou menos chuvoso do Estado do Pará, onde acontecem, normalmente, os maiores números de focos de calor provenientes da queima da biomassa vegetal, totalizando 183 dias, isto é, 4.393 horas de simulação, com saídas de dados das análises a cada hora, de forma a representar as características observadas durante o período estudado. O modelo foi configurado para duas grades tridimensionais aninhadas: 24 e $72 \mathrm{~km}$ de resolução espacial, centrada em 3,5 S e $51,25 \mathrm{~W}$ e $2,5 \mathrm{~S}$ e $51,5 \mathrm{~W}$, respectivamente, com pontos de grade em $\mathrm{x}$, y e $\mathrm{z}$ de 48, 40 e 32 para a primeira grade (Figura 2a) e de 86, 71 e 32, para a segunda (Figura 2b). Os níveis padrões das emissões atmosféricas de CO estudados cobriram altitudes com níveis de pressão de 1000, 925, 850, e 500 $\mathrm{hPa}$, que corresponde a $120,720,1.457$ e $5.574 \mathrm{~m}$ acima da superfície, respectivamente, com o topo do modelo em $200 \mathrm{hPa}$ ou $11.784 \mathrm{~m}$ de altura. 


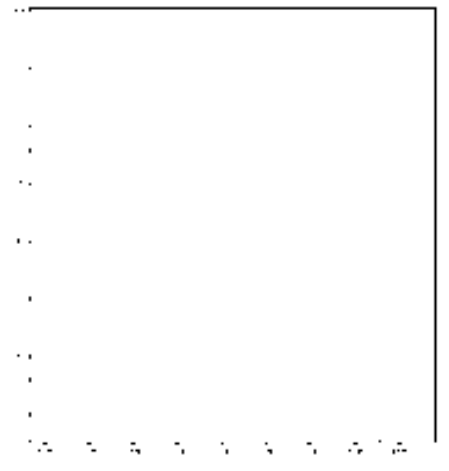

(a)

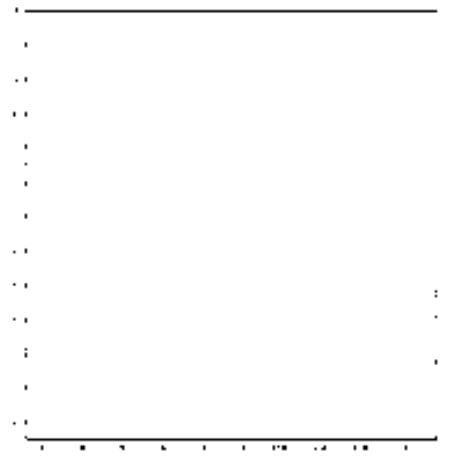

(b)

Figura 2 - Domínio das 2 grades utilizadas para o desenvolvimento do trabalho - Grade 1 - 24 km (a) e Grade 2 - 72 km (b)

\section{NÍVEIS OU PADRÕES LEGAIS DE QUALIDADE DO AR ATMOSFÉRICO}

A Resolução no 03/1990 do Conselho Nacional do Meio Ambiente CONAMA é o instrumento legal, que contém os padrões nacionais de qualidade do ar para, além de outras substâncias, o gás monóxido de carbono (CO), cujos valores primários (limite máximo tolerável para a saúde da população) e secundários (mais rigorosos, que prevê um mínimo de efeitos à população e ao meio ambiente) encontram-se descritos pela Tabela 1.

Tabela 1 - Padrões Nacionais de Qualidade do Ar de acordo com a Resolução CONAMA 03/1990.

\begin{tabular}{lclc}
\hline \multirow{2}{*}{ POLUENTE } & TEMPO DE & \multicolumn{2}{c}{ PADRÕES DE QUALIDADE DO AR } \\
\cline { 3 - 4 } & AMOSTRAGEM & \multicolumn{2}{c}{ PPm } \\
\cline { 3 - 4 } & & PADRÃO PRIMÁRIO & $\begin{array}{c}\text { PADRÃO } \\
\text { SECUNDÁRIO }\end{array}$ \\
\hline Monóxido de Carbono - & 1 hora & $40.000^{(1)}(35 \mathrm{ppm})$ & $40.000^{(1)}$ \\
CO & 8 horas & $10.000^{(2)}(9 \mathrm{ppm})$ & $10.000^{(2)}$ \\
\hline
\end{tabular}

Fonte: Resolução CONAMA no. 03/1990.

\section{ÁREA DE ESTUDO \\ RELEVO DO ESTADO DO PARÁ}

A geografia do Estado do Pará, que predomina vasto domínio de terrenos de modestas encostas, inferiores a $250 \mathrm{~m}$, inseridos no Domínio Morfoclimático das Terras Baixas Equatoriais da Amazônia, encontram-se: ao norte e sul terrenos mais elevados com cotas que atingem 600 a $800 \mathrm{~m}$ de altitude, e paralelamente à calha do rio Amazonas, assenta-se a Bacia Sedimentar do Amazonas, em uma direção aproximadamente longitudinal (E-W), com planaltos e baixos platôs ligeiramente mais elevados do que as superfícies de aplainamento circundantes (CPRM, 2012) (Figura 3). 


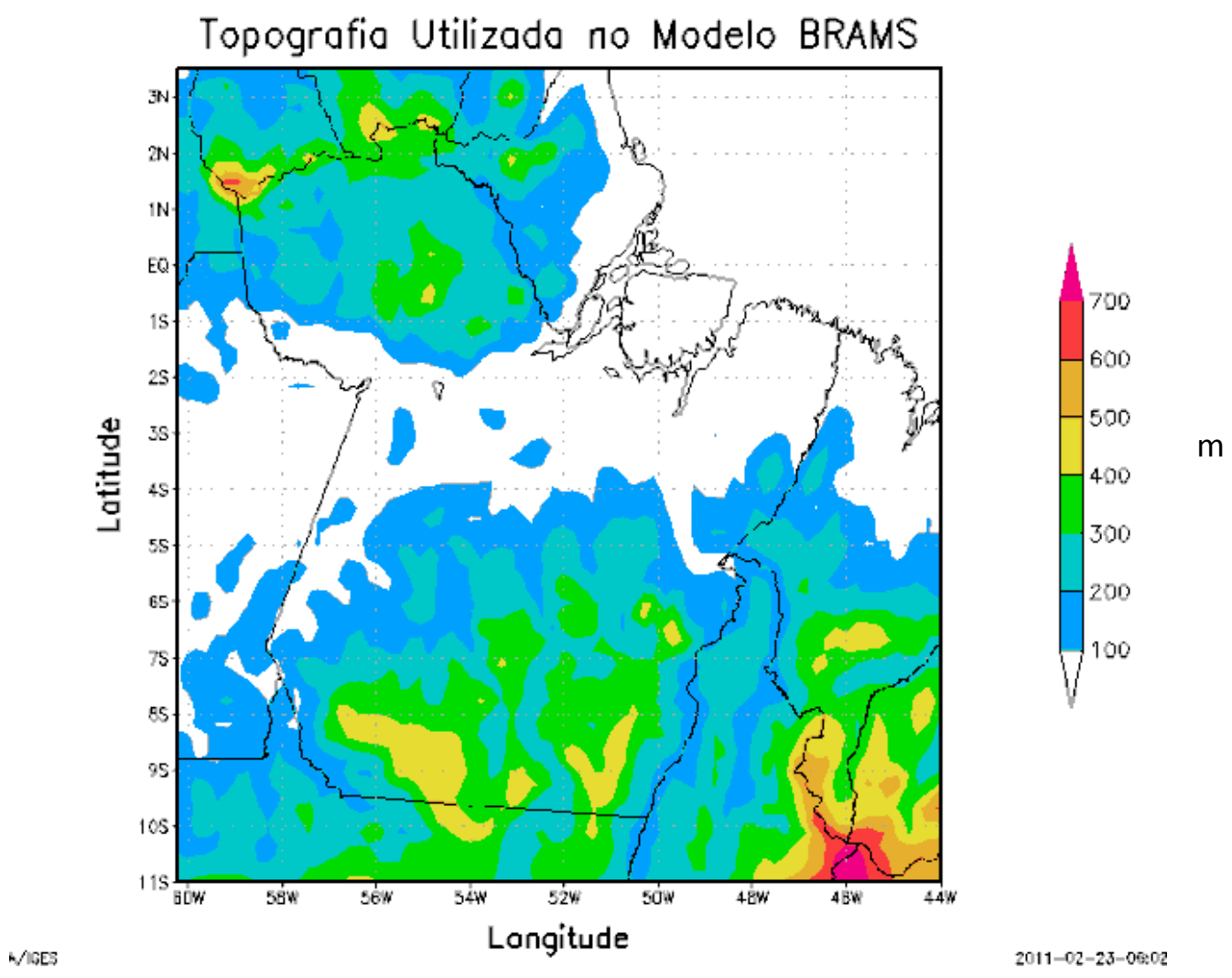

Figura 3 - Morfologia do Estado demonstrado pelo modelo BRAMS. A região em branco mostra o domínio da Planície Amazônica. Fonte: Laboratório de Modelagem da Amazônia - LAMAZ - UFPA

\section{VOLUME PLUVIOMÉTRICO}

Nos meses de junho e julho de 2010 é nítida a divisão do Estado em dois padrões de chuva, sendo o norte mais chuvoso e o sul mais seco (Figura 4) indicando que a Planície Sedimentar Amazônica (Figura 3) configurou-se como uma espécie de divisor de águas entre as regiões ao norte e ao sul do Pará. Nos meses de agosto e setembro se verifica apenas pequenas ilhas de chuvas ao norte do Estado, e em outubro e novembro, ao contrário do período anterior, houve a formação apenas, de pequenas ilhas de baixa precipitação no centro e ao norte do Estado (Figura 4). Desta forma, os meses que apresentaram, respectivamente, menor precipitação na maior parte da região de estudo foram agosto e setembro do ano de 2010, apresentado valores variando de 5 até 150 $\mathrm{mm}$.

As mesorregiões Sudoeste e parte da Sudeste se destacaram apresentando os maiores índices pluviométricos, e as mesorregiões do Baixo Amazonas e Marajó apresentaram menores índices, com volumes pluviométricos de 25 a $150 \mathrm{~mm}$, porém com a porção Noroeste apresentando os maiores índices (Figura 4). O mesmo ocorreu com a mesorregião Nordeste paraense com baixos volumes pluviométricos variando de 3 a $50 \mathrm{~mm}$ (Figura 4). Em outubro voltou a chover em grande parte do Pará, ficando, apenas, parte da planície amazônica e os vales do Tapajós e Xingu com índices abaixo de $50 \mathrm{~mm}$. No final do período estudado, no mês de novembro, quase todo o Estado esteve sob o 
regime de índices pluviométricos em torno de $100 \mathrm{~mm}$ (Figura 4). Toda esta variação do volume pluviométrico ocorrido no Estado foi associada a pulsos da ZCIT, convecção local e circulação de brisas provocadas pelo aquecimento e pela elevada umidade na região (RPCH, 2010).
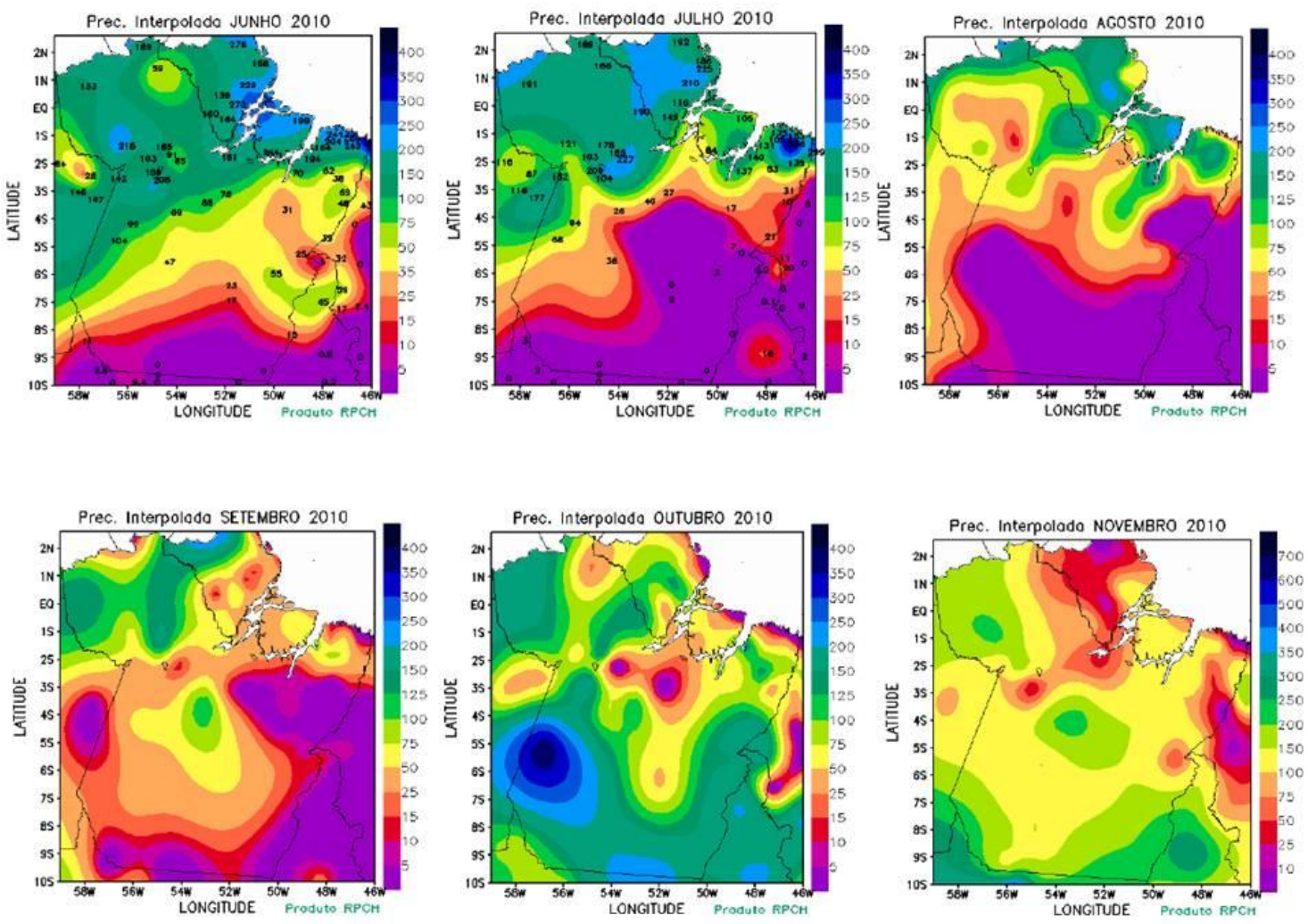

$\mathrm{mm}$

Figura 4 - Acumulado da precipitação mensal em mm, nos meses de junho, julho, agosto, setembro, outubro e novembro do ano de 2010, para o Estado do Pará. Os dados de precipitação acumulada foram gerados por 15 estações meteorológicas do INMET, localizadas no Pará, e processados pela Rede Estadual de Previsão Climática e Hidrometeorológica do Pará (RPCH). A escala de cores indica o volume de chuva acumulada, em mm.

\section{MODELO DE DESENVOLVIMENTO ECONÔMICO DO PARÁ}

No Estado do Pará as atividades industriais existem em todas as mesorregiões do Estado, com concentração significativa nas mesorregiões Metropolitana de Belém, Nordeste e Sudeste do Pará (Figura 5). Mesmo com um modelo tradicional de desenvolvimento econômico predatório e extrativista, essas mesorregiões se destacaram devido ao maior desenvolvimento dos setores agropecuário e florestal, sobressaindo a produção de carvão vegetal e a indústria madeireira na parte central da mesorregião Sudoeste (Figura 6). O restante da mesorregião Sudoeste, e as do Marajó e Baixo Amazonas apresentaram-se com menor expressividade, onde os efeitos espaciais do desenvolvimento econômico ainda são pouco significativos. 
DISTRIBUICÃO DAS ATIVIDADES POLUIDORAS DO ESTADO DO PARÁ

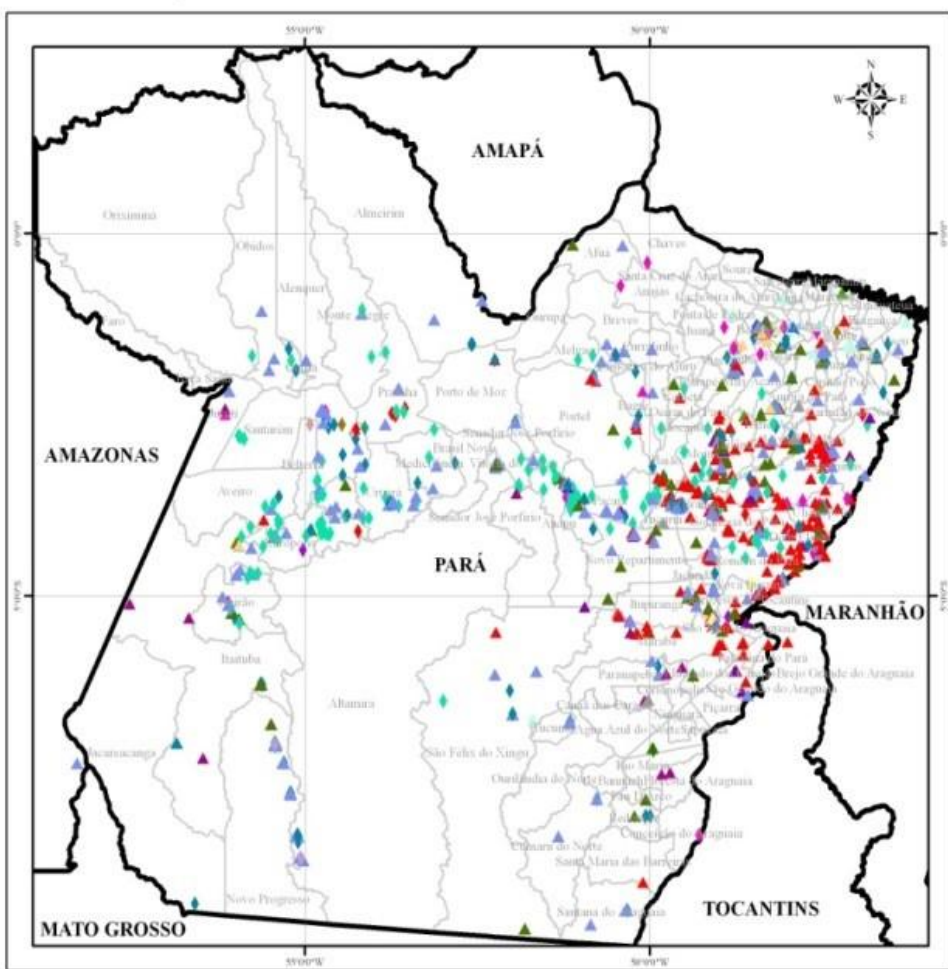

LEGENDA

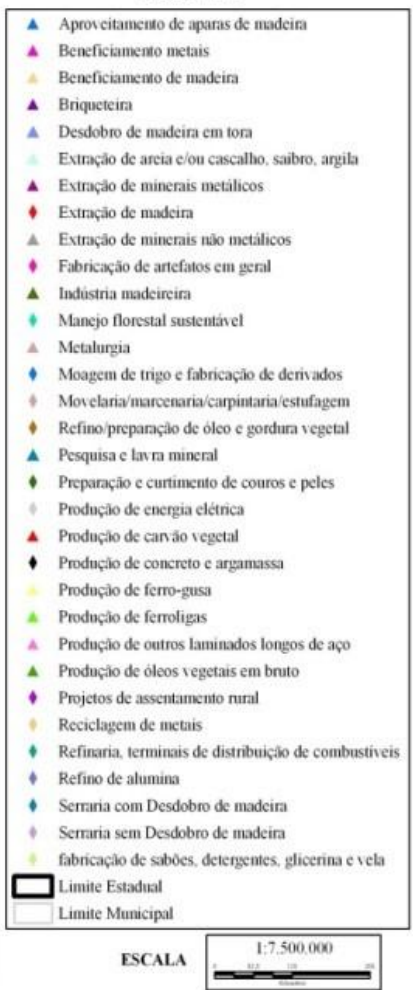

Figura 5 - Distribuição de 1400 empreendimentos referentes a 32 atividades econômicas potencialmente poluidoras em operação no Estado do Pará. Fonte: Projeto REMAM - Rede de Monitoramento de Eventos Extremos da Amazônia

Atualmente, o crescente processo de expansão da maior fronteira agrícola em ampliação no mundo inspira intensas preocupações, com a predominância do cultivo de grãos, principalmente soja, na região denominada de "arco do desflorestamento ou do desmatamento", que já atinge 1.000.000 ha, e se estende das regiões sudeste e sudoeste do Pará (MORTON et al., 2006). Esta atividade econômica acarretou e ainda responde por significativos desmatamentos e degradação da área florestada do Estado, causando inúmeros e severos impactos ao ecossistema florestal e sendo fonte de enormes quantidades de gases para a atmosfera advindo da queima de biomassa, que acarreta, ao intensificar essa fronteira agrícola, considerada como fonte poluidora, a eliminação dos serviços ecossistêmicos realizados pelas florestas amazônicas (adaptado de FEARNSIDE, 2008).

Todas essas atividades econômicas e, principalmente, as queimadas são fontes de emissões atmosféricas classificadas como antropogênicas, estacionárias e múltiplas e, dentre as concentrações de gases traço e o CO são objeto deste estudo. Isto se deve ao seu potencial de contaminação do ar e de provocar efeitos adversos agudos e crônicos à saúde humana e ao meio ambiente, tais como: intensificação do efeito estufa e a sua consequente modificação no balanço radioativo do Planeta, acarretando o descontrole climático em uma dimensão global, distúrbios respiratórios e lesões degenerativas no sistema nervoso (ALVES et al., 2015; MATA et al., 2017; REGALADO et al., 2006; SIGSGAARD et al., 2015). 


\section{RESULTADOS E DISCUSSÃO}

\section{FOCOS DE FOGO OCORRIDOS NO PERÍODO}

No período estudado, de junho a novembro de 2010, os meses de agosto e setembro destacaram-se como os de maior número de focos de queima da biomassa vegetal do Pará, merecendo destaque o mês de agosto, com o máximo detectado pelo sensoriamento remoto utilizado (MODIS ModerateResolution Imaging Spectroradiometer) e AVHRR (Advanced Very High Resolution Radiometer) de 70.648 focos de queimadas, não podendo desprezar o mês de setembro com 58.109 focos, de acordo com os registros disponibilizados pelo INPE, 2010. Tal cenário já era esperado, pois este período é considerado crítico em termos de intensificação das práticas da agricultura tradicional, de queima aplicada às atividades de abertura e expansão das áreas agrícolas, renovação das áreas de pastagens (pecuária), aliado ao uso do fogo pelos pequenos produtores na agricultura de corte e queima. Aliada a este cenário ocorre também, neste período, a queima da biomassa vegetal associada às atividades predatórias no uso e ocupação do solo, como desmatamento e queimadas propositais e a exploração madeireira, que se intensificam nos meses de agosto e setembro. As mesorregiões Nordeste, Sudeste e Sudoeste do Estado destacaram-se como as mais afetadas pela queima da biomassa vegetal, no período analisado, sendo que estas regiões se caracterizaram por apresentar, pelo menos três meses com índice pluviométrico abaixo de $150 \mathrm{~mm}$.mes-1 (Figuras 4). Merecem destaques também, neste contexto, as emissões provenientes das atividades industriais, mais concentradas nas duas regiões anteriormente referenciadas (Figura 5). 


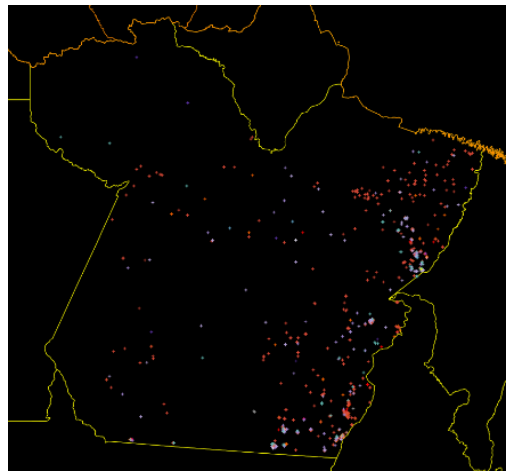

(a)

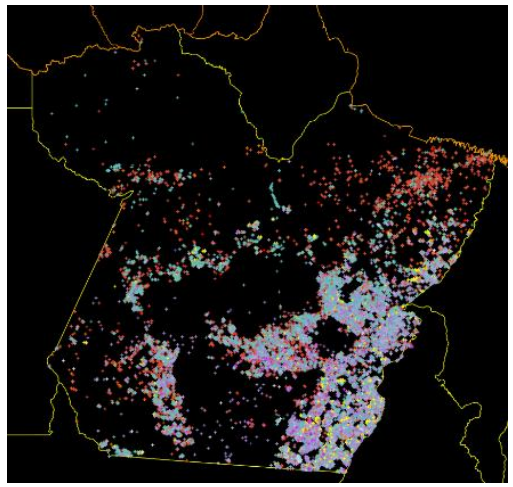

(d)

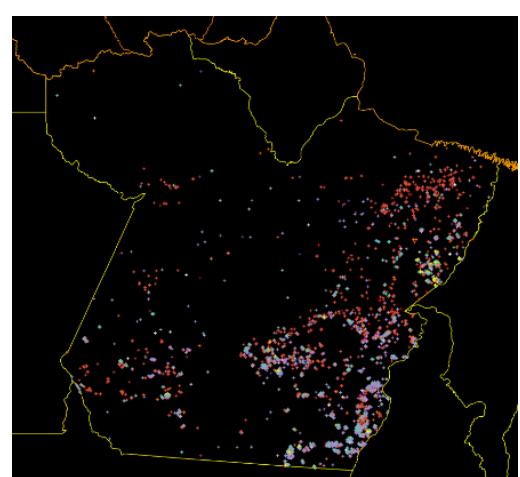

(b)

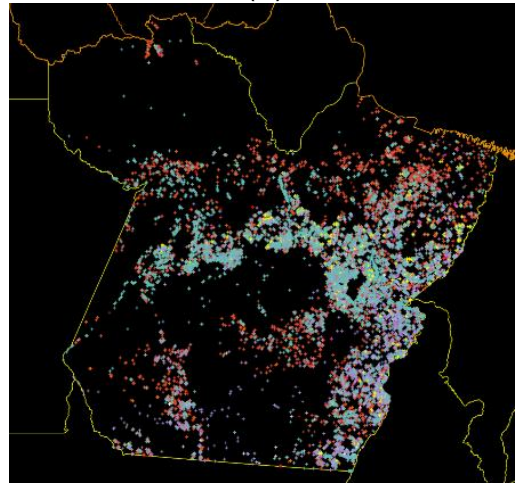

(e)

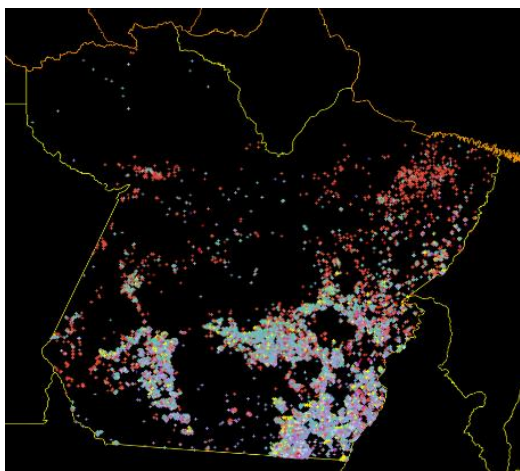

(c)

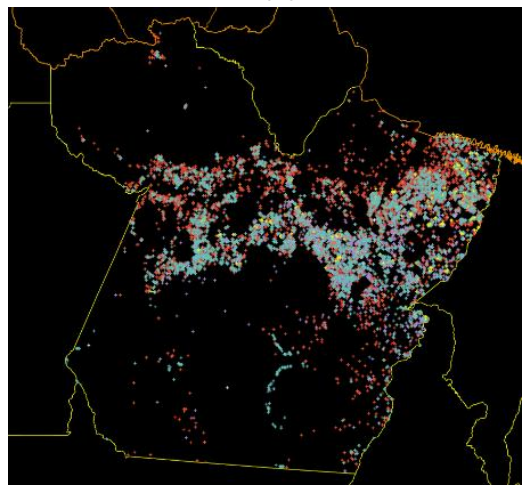

(f)

Figura 6- Focos de calor detectados pelos sensores MODIS Moderate-Resolution Imaging Spectroradiometer e AVHRR (Advanced Very High Resolution Radiometer) no período de junho (a), julho (b), agosto (c), setembro (d), outubro (e) e novembro (f) de 2010. Os símbolos em marrom representam os registros do satélite de referência AQUA; em vermelho e laranja, satélite TERRA (manhã e noite); azul claro, GOES; amarelo MSG02; lilás, branco, tons em rosa e verde claro, satélites NOAA 15, 16, 17, 18 e 19.Fonte: Banco de Dados de Queimadas (BDQUEIMADAS) do INPE/CPTEC, na região do Pará

\section{TRANSPORTE E DISPERSÃO DAS EMISSÕES DE CO}

Os resultados das simulações realizadas indicaram que tanto os valores, quanto a área de abrangência das concentrações de CO (ppbv), se elevaram progressivamente e significativamente com a intensificação do período seco, em todas as regiões do Estado (Figura 7). No nível de pressão de $1000 \mathrm{hPa}$, (nível próximo à superfície, aproximadamente $120 \mathrm{~m}$ de altitude) as concentrações médias mensais simuladas de $\mathrm{CO}$ aumentaram e atingiram valores que variaram de 10.000 a 300.000 ppbv, a partir do mês de agosto, permanecendo com esta tendência de elevação até o mês de novembro (Figura 7). 

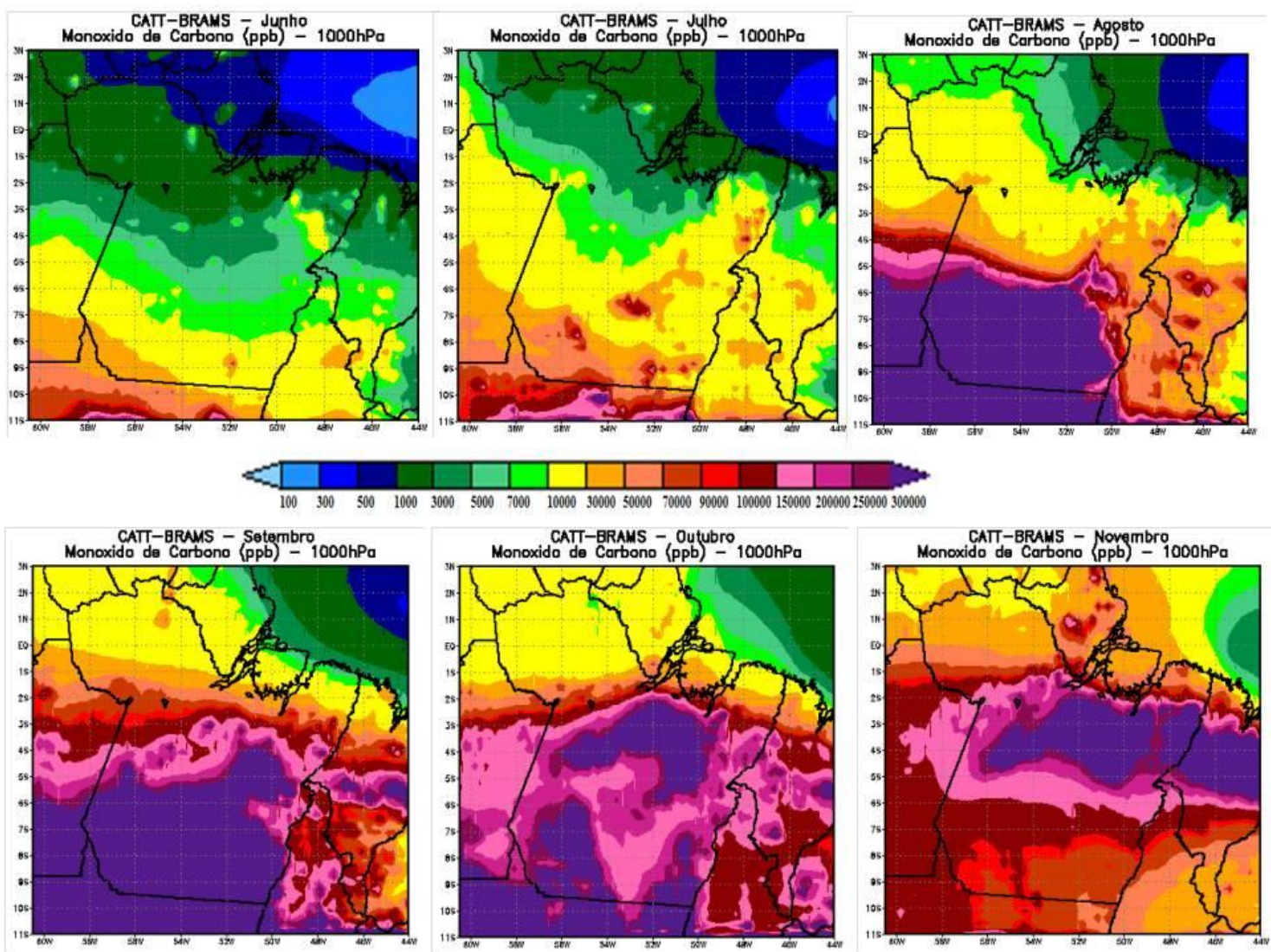

Figura 7 - Acumulados Mensais de Monóxido de Carbono - CO (ppbv) no nível Geopotencial de $1000 \mathrm{hPa}$, simulados pelo CATT-BRAMS durante os meses secos, em junho, julho, agosto, setembro, outubro e novembro de 2010, no Estado do Pará

Além disto, os valores máximos apresentados indicaram simulações sobre áreas com elevadas concentrações de focos de incêndio, onde as plumas são mais intensas e ainda não significativamente dispersas, confirmando assim a descrição apresentada por Freitas et al. (2005). De fato, esse cenário é comprovado pela ocorrência, no Pará, de inúmeros focos de queima neste período (Figura 6), caracterizado pelo aumento progressivo na quantidade de focos de queima da biomassa vegetal do Estado a partir do mês de junho, com pico máximo em agosto e setembro de 70.648 e 58.109 focos, respectivamente, conforme descrito acima (Figura 6).

Nota-se que o perfil vertical de CO do nível de 1000 (Figura 7) e de 925 até $200 \mathrm{hPa}$ (acima de $11 \mathrm{~km}$ de altitude) (Figura 8), a cada mês estudado aumentou progressivamente até a altura de $500 \mathrm{hPa}$, proporcionalmente, ou seja, uma grande parte das emissões de CO, originada na superfície, foi transportada do nível mais baixo para os níveis mais elevados (Figura 8). Um fator importante identificado pelas simulações realizadas foi a similaridade dos perfis das concentrações de CO, desde a superfície até os níveis de 925 e 850 hPa. Tal cenário concorda com Freitas (1999), Freitas et al. (2005) e Santos et al. (2017), os quais afirmam que a mistura turbulenta da camada limite 
transporta verticalmente as emissões de poluentes lançadas à atmosfera, tendendo a homogeneizá-los por toda a camada de mistura (Figura 8). Entretanto, o nível mais alto $(200 \mathrm{hPa})$ da atmosfera recebe CO de outras regiões ou acumula o $\mathrm{CO}$ produzido anteriormente, pois como pode constatar as concentrações ao nível de $200 \mathrm{hPa}$ estão sempre acima ou igual as concentrações dos níveis mais baixos (Figura 8)
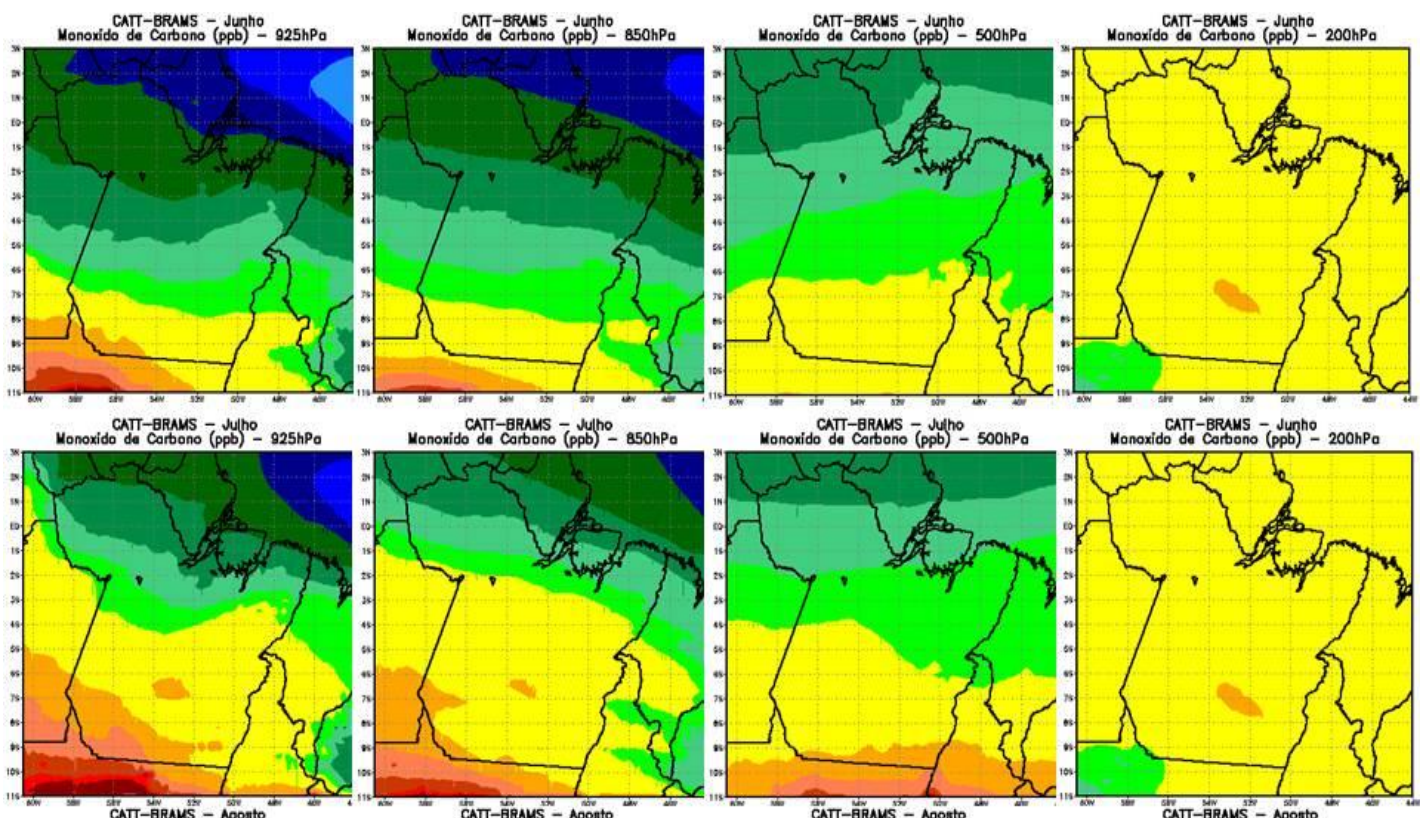

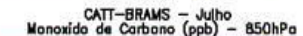
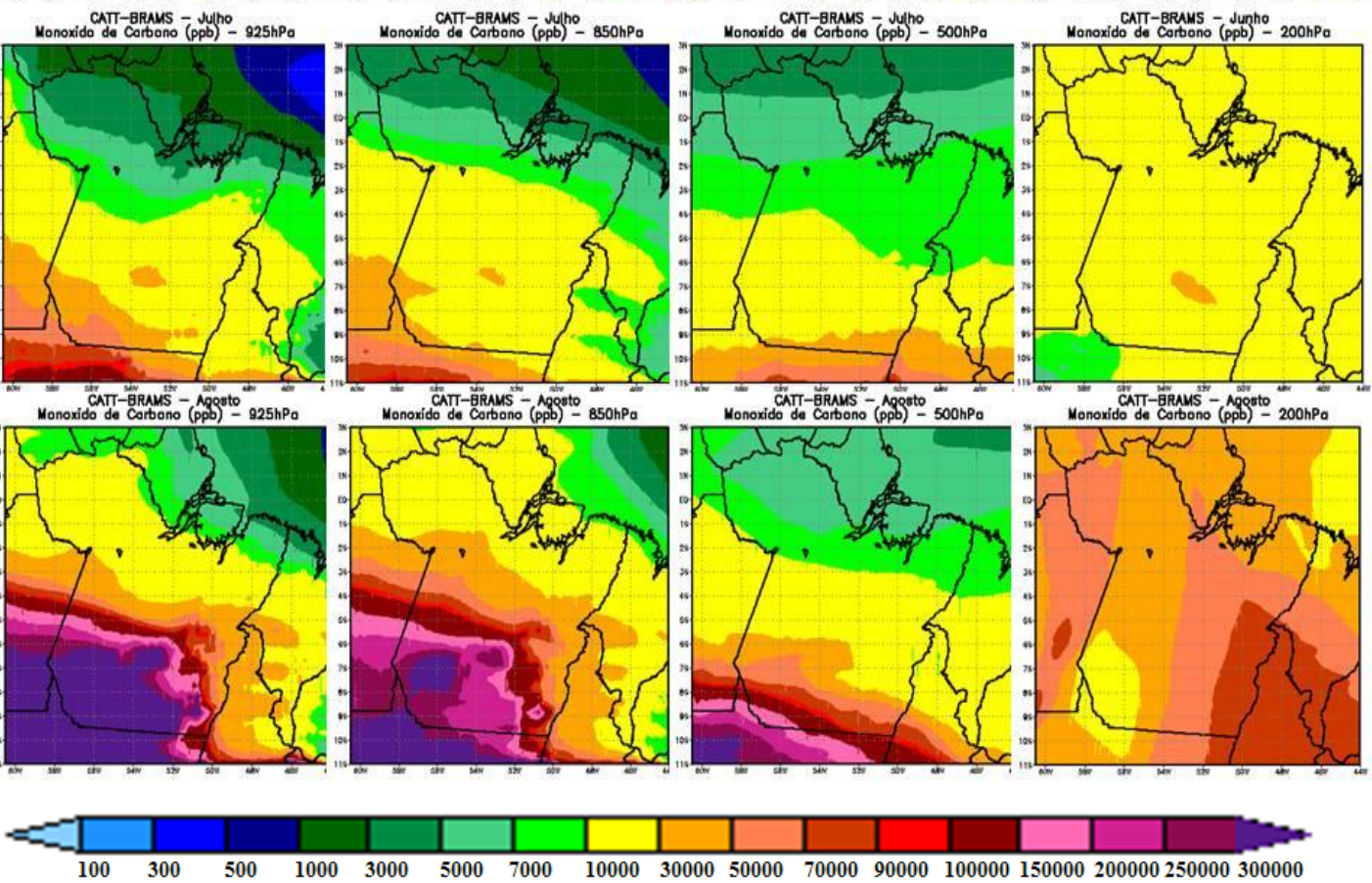

Figura 8 - Acumulados Mensais de Monóxido de Carbono - CO (ppbv) no nível geopotencial de $200 \mathrm{hPa}$, simulados pelo CATT-BRAMS, em junho, julho, agosto, setembro, outubro e novembro 

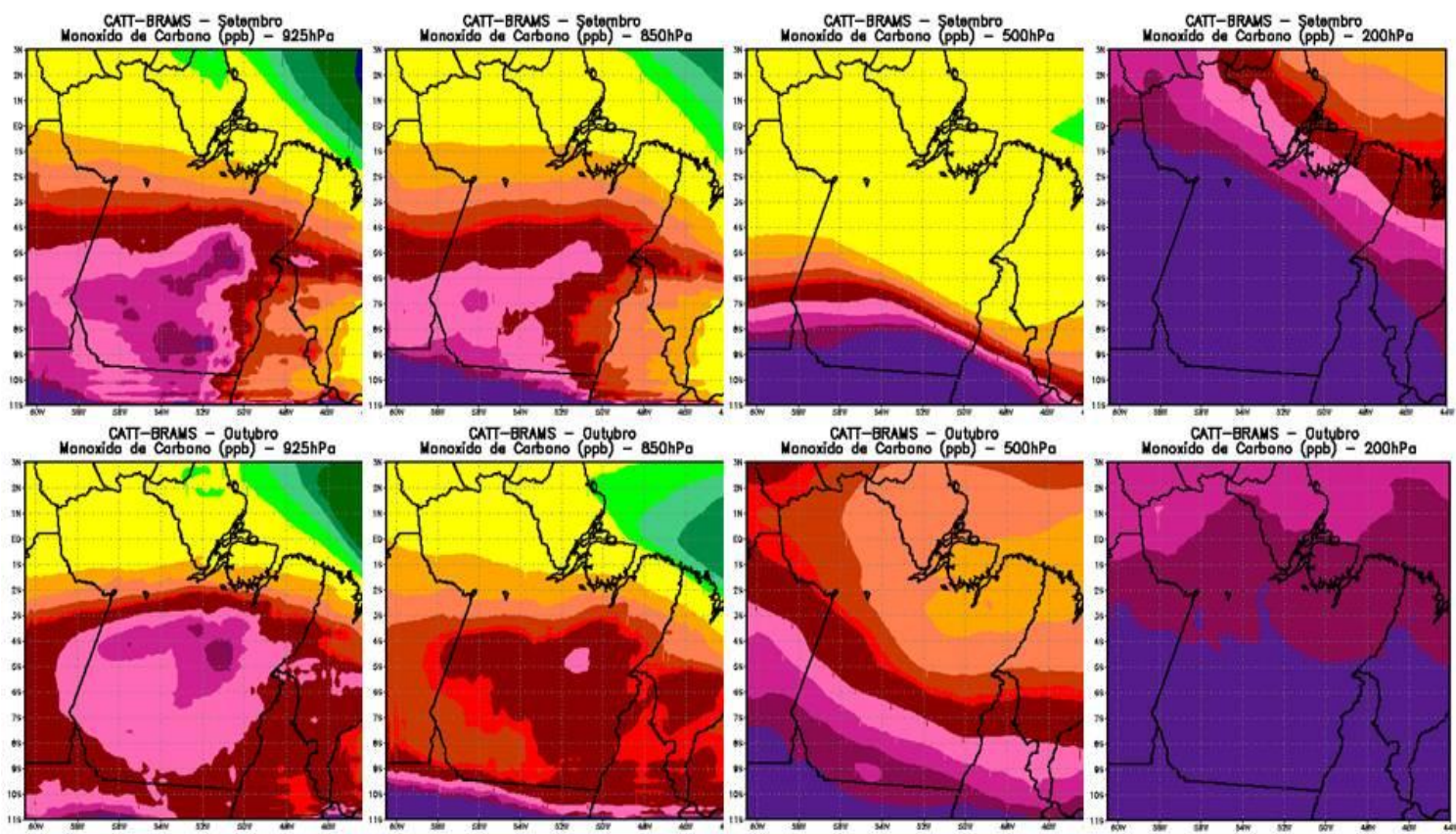

CATT-BRAMS - Outubro CATT-BRAMS - Outubro
Monoxido de Corbono (ppb) $-200 \mathrm{hPo}$
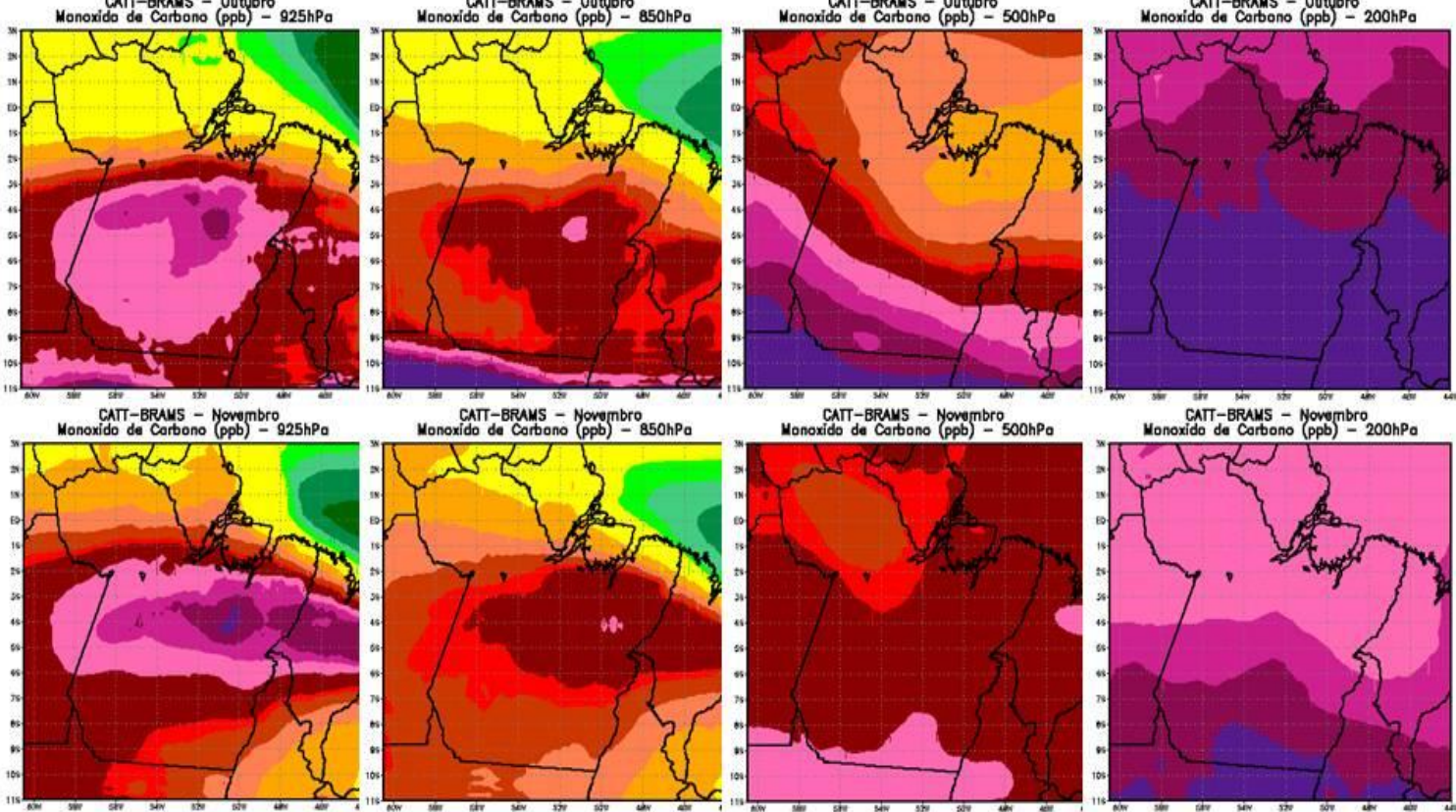

CATT-BRaus - Nowombro
Monoxido de Corbono $(\mathrm{pob})-500 \mathrm{hPa}$

CATT-BRAMS - Novembro
Monoxido de Cortono (ppb) $-200 \mathrm{hPo}$
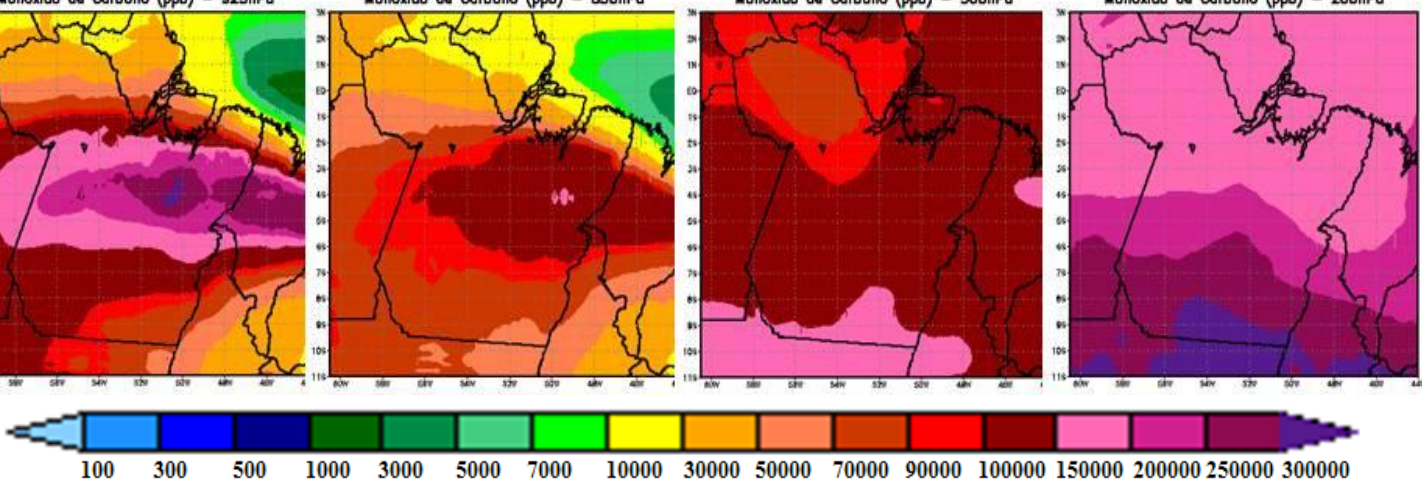

Continuação Figura 8

O índice pluviométrico reduzido, ou praticamente zerado em algumas regiões do Estado, e o agravante do aumento das queimadas, associados aos sistemas convectivos profundos, à movimentação de massas de ar que ocorreram na região, devido à flutuação positiva das emissões provenientes das queimadas da biomassa vegetal, contribuem para manter grande parte das emissões de $\mathrm{CO}$ em suspensão na atmosfera, e a consequente redistribuição vertical dessas emissões, chegando a alcançar elevados níveis da atmosfera (FREITAS, 1999; SEINFELD; PANDIS, 2016). Segundo Andreae et al. (2012) a atmosfera da floresta amazônica tem uma razão de mistura de CO em torno de 100 ppbv, entretanto, o influxo médio da razão de mistura de CO na Bacia Amazônica durante o período SAMBBA a $500 \mathrm{hPa}$, variou entre 140 e 160 ppbv (SANTOS et al., 2017). Muito deste CO encontrado na média atmosfera é devido ao transporte de longo alcance de queima de biomassa ocorrida na África e na parte oriental da Amazônia (ALONSO et al., 2010; SANTOS et al., 2017).

Observou-se também, ao analisar essas altitudes mais baixas (1000, 925 e $850 \mathrm{hPa}$ ) a importante participação das regiões oeste e noroeste do Estado do 
Mato Grosso nos meses de junho até outubro, e da região central e sul do Estado do Maranhão no mês de novembro, na produção de CO que adentra o Estado do Pará, contribuindo para um aumento na concentração de CO em todas as camadas estudadas (Figura 8). Este cenário fornece um forte indicativo da significativa influência das práticas aplicadas na área agrícola de plantio de grãos, principalmente de soja, na região denominada de "arco do desmatamento" (uma área em torno da latitude $10^{\circ} \mathrm{S}$ entre a longitude $67^{\circ} \mathrm{W}$ e $50^{\circ} \mathrm{W}$ e na latitude $10^{\circ} \mathrm{S}$ a $5^{\circ} \mathrm{S}$ em torno da longitude $50^{\circ} \mathrm{W}$ ), em grande expansão nos Estados do Mato Grosso, Pará e Maranhão (Figura 7) com um forte gradiente de emissões de $\mathrm{CO}$, chegando até $1.500 \mathrm{mg} C O \mathrm{~m}-2$ dia-1 (LONGO et al., 2010). Contudo uma parte desta concentração de CO que adentra a Amazônia pela planície, pode também ser resultante de queima de biomassa em ecossistemas no oeste da África (ANDREAE et al., 2012).

É importante ressaltar que setembro é o mês que marca o final da estação seca nos Estados ao sul do Pará, e novembro é o final da estação seca nos Estados a leste do Estado, o que mostra uma diminuição acentuada nas concentrações de CO (LONGO et al., 2010), as quais não foram confirmadas por este estudo. Ainda, ressalta-se a grande concentração de indústrias de produção de carvão vegetal (carvoarias) na mesorregião Sudeste paraense, principalmente próximo ao limite com o Estado do Maranhão (Figura 5). Estes dois fatores podem em conjunto estar movimentando as plumas de poluição de CO para o oeste do Pará e ao mesmo tempo limpando a atmosfera dos agentes poluidores. Este cenário pode ser atribuído ao processo de dispersão/transporte de massas de ar de áreas "poluídas" circunvizinhas ao Pará, cujas concentrações foram somadas às que foram geradas em território paraense e foram advectadas por ação dos ventos alísios de leste para o oeste, em direção ao Estado do Amazonas (FREITAS et al., 2009). De grande importância também nesse cenário é o relevo da região do Estado (Figura 4), composta por terrenos de cotas modestas, inferiores a $250 \mathrm{~m}$, sendo que a planície sedimentar do Amazonas produz uma forte movimentação de massa de ar do oceano para o continente, levando grande parte das emissões para as regiões mais a oeste do Estado.

Simulações de distribuições de CO usando vários modelos, concordaram na distribuição espacial do $\mathrm{CO}$ e confirmar a importante contribuição das emissões de queima de biomassa, que forneceram cerca de $30 \%$ dos valores absolutos e foram responsáveis por aproximadamente $95 \%$ da variabilidade do CO (ANDREAE et al., 2012). Contudo, os mesmos autores revelam que estes modelos demonstram algumas diferenças quantitativas e sistemáticas comparadas às concentrações observadas de CO. Se os eventos extremos continuarem a ser mais constantes, neste caso o El Niño, as reduções na precipitação e no armazenamento de água terrestre devem aumentar as emissões de fogo nas florestas tropicais em $133 \%$ durante e após o El Niño em comparação com o La Niña (CHEN et al., 2017).

Comparando os valores das concentrações simuladas de $\mathrm{CO}$ com os padrões estabelecidos pela Resolução do Conselho Nacional de Meio Ambiente CONAMA no. 03/1990, apresentadas pela Tabela 1 , verificou-se que as concentrações de $\mathrm{CO}$ na atmosfera ultrapassaram o valor máximo permitido de 9 ppmv, para $8 \mathrm{~h}$ de exposição, continuadamente nas mesorregiões Sudeste e Sudoeste paraense, a partir do mês de junho de 2010, até o final do período estudado, em novembro. O valor máximo permitido de $35 \mathrm{ppmv}$ para $1 \mathrm{~h}$ de 
exposição, foi ultrapassado, cada vez em maiores proporções, a partir do mês de julho, até novembro de 2010. Tal cenário se deve a vários fenômenos ocorridos no Estado, neste período, dentre eles os mais importantes e que puderam ser observados pelos estudos e simulações realizadas foram: diminuição do índice pluviométrico, intensificação das queimadas que normalmente ocorrem na região de estudo e a contribuição de plumas de emissões de CO provenientes das regiões circunvizinhas ao Pará.

\section{CONCLUSÃO}

As simulações realizadas no período de junho, julho, agosto, setembro, outubro e novembro de 2010, evidenciaram que as emissões de CO se dispersaram e foram transportadas, devido à intensidade dessas emissões, aos efeitos do escoamento atmosférico, ao regime das chuvas, à direção e velocidade dos ventos e às condições topográficas do Pará, atingindo elevadas altitudes, várias regiões do Estado e de outras regiões circunvizinhas.

Com relação ao perfil econômico do Estado foi demonstrado que dentre as seis mesorregiões paraense, a Sudeste e Nordeste (incluindo a Metropolitana de Belém) se destacaram devido ao maior dinamismo dos setores agropecuário, florestal e industrial, e a parte central da mesorregião Sudoeste com, basicamente, a indústria florestal. O restante da mesorregião Sudoeste e as do Marajó e Baixo Amazonas apresentaram-se com menor expressividade, onde os efeitos espaciais do desenvolvimento econômico ainda são pouco significativos.

Estas atividades são classificadas como fontes de origem e de lançamento de grandes concentrações de gases traço, como o CO à atmosfera, devido às suas características operacionais como a prática do desmatamento e da queima da biomassa vegetal, necessárias à limpeza das áreas de pastagens (grandes proprietários) nas atividades agropecuárias e florestais e à queima da capoeira pela agricultura familiar.

O relevo do Estado possui uma forte responsabilidade nesse cenário: predominantemente composto por terrenos de cotas modestas inferiores a 250 $m$, provocaram significativa movimentação de poluentes atmosféricos vindos de outros Estados (principalmente do Maranhão e Tocantins) e a planície sedimentar amazônica produziu uma movimentação de massa de ar do oceano para o continente, levando grande parte desses poluentes para as regiões mais a oeste.

O mês de agosto se destacou como o mais seco do período estudado com índices da ordem de 5 a $100 \mathrm{~mm}$, seguido dos meses de setembro, julho, junho, novembro e outubro, respectivamente, e como o de maior número de focos de fogo registrados pelo INPE, que foi de 70.648 focos, com as maiores concentrações das fontes de origem nas mesorregiões Nordeste, Sudeste e Sudoeste do Estado, e menores nas mesorregiões do Baixo Amazonas e Marajó.

Considerando todos os aspectos identificados, os acumulados mensais de $\mathrm{CO}$, simulados demonstraram que próximo à superfície, no nível geopotencial de $1000 \mathrm{hPa}$, as concentrações destes poluentes se elevaram à medida em que o período se tornou mais seco e os focos de fogo se intensificaram, principalmente nas mesorregiões Nordeste, Sudeste e Sudoeste.

Com grande variação durante o período estudado, estas concentrações atingiram valores mínimos de 500 e máximos de 300.000 ppbv $(0,5$ a 300 
ppmv), do início até o fim do período de estiagem, ultrapassando, a partir do mês de junho, o padrão de qualidade do ar previsto para 1 hora de exposição, de 9 ppmv, e de 35 ppmv para 8 horas de exposição, com destaque as mesorregiões Sudeste, Sudoeste e, seguidas da Nordeste paraense.

Os resultados simulados das emissões de CO evidenciaram que emissões provenientes das áreas "poluídas" circunvizinhas ao Pará, somadas às geradas à sudeste, extremo sul e sudoeste do Estado, foram advectadas pelos ventos alísios de leste para o oeste, em direção ao Estado do Amazonas. Com relação ao transporte vertical das plumas dos poluentes simulados, o modelo evidenciou também que as emissões de $\mathrm{CO}$, próximo à superfície do solo, atingiram níveis de altitudes mais elevadas de $200 \mathrm{hPa}$, devido aos processos convectivos ascendentes que atuam nas regiões tropicais, isto é devido à ação da flutuação positiva que essas emissões, associadas às queimadas da biomassa vegetal e às atividades industriais, adquirem em função do gradiente de temperatura existente entre elas e o ambiente.

Com as informações geradas por este trabalho, pode-se afirmar que o Estado do Pará, principalmente as mesorregiões Nordeste, Sudeste e Sudoeste, teve a sua qualidade do ar, em termos das concentrações de $\mathrm{CO}$, degradada, chegando a ultrapassar os padrões legais permitidos, durante o período seco de 2010.

Tal cenário evidencia e confirma o já referenciado desrespeito e a influência negativa da ação antrópica sobre os recursos naturais do Estado, com uma economia tradicionalmente calcada em atividades agropastoris e madeireiras predatórias e explorações minerais e florestais, presentes numa "escala basicamente extrativa", todas elas, inserindo em seu contexto, práticas de desflorestamentos (desmatamentos), seguidas de queimadas de grandes áreas de florestas.

Com estes resultados pode-se observar e salientar o grave e iminente risco de, no Estado do Pará, haver problemas na saúde humana e no meio ambiente, principalmente nas mesorregiões Sudeste e Sudoeste paraense, pois o CO possui características danosas à saúde humana.

\section{REFERÊNCIAS BIBLIOGRÁFICAS}

ALBUQUERQUE, M. F. DE; SOUZA, E. B. DE. Distribuição Espacial da Precipitação Climatológica nas Mesorregiões do Estado do Pará, nas Últimas Décadas ( 1978-. p. 1-5, 2008.

ALMEIDA, C. A. DE et al. High spatial resolution land use and land cover mapping of the Brazilian Legal Amazon in 2008 using Landsat-5/TM and MODIS data. Acta Amazonica, v. 46, n. 3, p. 291-302, set. 2016.

ALONSO, M. F. et al. An urban emissions inventory for South America and its application in numerical modeling of atmospheric chemical composition at local and regional scales. Atmospheric Environment, v. 44, n. 39, p. 5072-5083, 2010.

ALVES, N. DE O. et al. Biomass burning in the Amazon region: Aerosol source apportionment and associated health risk assessment. Atmospheric Environment, v. 120, p. 277-285, 1 nov. 2015. 
ANDREAE, M. O. et al. Biogeochemical cycling of carbon, water, energy, trace gases, and aerosols in Amazonia: The LBA-EUSTACH experiments. Journal of Geophysical Research D: Atmospheres, v. 107, n. 20, 2002.

ANDREAE, M. O. et al. Carbon monoxide and related trace gases and aerosols over the Amazon Basin during the wet and dry seasons. Atmospheric Chemistry and Physics, v. 12, n. 13, p. 6041-6065, 13 jul. 2012.

ANDREAE, M. O.; CRUTZEN, P. J. Atmospheric Aerosols: Biogeochemical Sources and Role in Atmospheric Chemistry. Science, v. 276, n. 5315, p. 1052-1058, 16 maio 1997.

ARTAXO, P. et al. Química atmosférica na Amazônia: a floresta e as emissões de queimadas controlando a composição da atmosfera amazônica. Acta Amazonica, v. 35, n. 2, p. 185-196, 2005.

BARBER, C. P. et al. Roads, deforestation, and the mitigating effect of protected areas in the Amazon. Biological Conservation, v. 177, p. 203-209, 1 set. 2014.

CHEN, Y. et al. A pan-tropical cascade of fire driven by El Niño/Southern Oscillation. Nature Climate Change, v. 7, n. 12, p. 906-911, 2017.

CRUTZEN, P. J. et al. Biomass burning as a source of atmospheric gases CO, H2, $\mathrm{N} 2 \mathrm{O}, \mathrm{NO}, \mathrm{CH} 3 \mathrm{Cl}$ and COS. Nature, v. 282, p. 253-256, 1979.

FEARNSIDE, P. M. Humans and the Environment in Amazonia. October, $\mathrm{n}$. October 2001, 2002.

FEARNSIDE, P. M. Quantificação Do Serviço Ambiental Do Carbono Nas Florestas Amazônicas Brasileiras. Oecologia Australis, v. 12, n. 04, p. 743-756, 2008.

FREITAS, M. A. B. et al. Floristic impoverishment of Amazonian floodplain forests managed for açaí fruit production. Forest Ecology and Management, v. 351, p. 20-27, 2015.

FREITAS, S. R. Modelagem Numérica do Transporte e das Emissões de Gases Traço e Aerossóis de Queimadas no Cerrado e Floresta Tropical da América do Sul. [s.I.] Universidade de São Paulo, 1999.

FREITAS, S. R. et al. Monitoring the transport of biomass burning emissions in South America. Environmental Fluid Mechanics, v. 5, n. 1-2, p. 135-167, 2005.

FREITAS, S. R. et al. The Coupled Aerosol and Tracer Transport model to the Brazilian developments on the Regional Atmospheric Modeling System (CATTBRAMS) - Part 1: Model description and evaluation. Atmospheric Chemistry and Physics, v. 9, n. 8, p. 2843-2861, 28 abr. 2009.

FREITAS, S. R. et al. Impact of a monotonic advection scheme with low numerical diffusion on transport modeling of emissions from biomass burning. Journal of Advances in Modeling Earth Systems, v. 3, n. 1, p. 1-26, 2012.

GÁCITA, M. S. et al. MELHORIA DO INVENTÁRIO DE EMISSÕES PARA A MODELAGEM DA QUALIDADE DO AR EM CUBA . 2007.

GALVÃO, M. F. DE O. et al. Biomass burning particles in the Brazilian Amazon region: Mutagenic effects of nitro and oxy-PAHs and assessment of health risks. Environmental Pollution, v. 233, p. 960-970, 1 fev. 2018.

GASH, J. H. C. et al. Amazonian climate: Results and future research. Theoretical and Applied Climatology, v. 78, n. 1-3, p. 187-193, 2004. 
GUENTHER, A. et al. A global model of natural volatile organic compound emissions. JOURNAL OF GEOPHYSICAL RESEARCH, v. 100, n. 20, p. 8873-8892, 1995.

IBGE. Dados do Censo 2010 publicados no Diário Oficial da União do dia 04/11/2010. Brasilia: [s.n.].

INPE. Prodes: Monitoramento da floresta Amazônica por satélite. Disponível em: <http://www.obt.inpe.br/prodes/prodes_1988_2015n.htm>. Acesso em: 20 maio. 2018.

KAUFMAN, Y. J. et al. Smoke, Clouds, and Radiation-Brazil (SCAR-B) experiment. Journal of Geophysical Research: Atmospheres, v. 103, n. D24, p. 31783-31808, 27 dez. 1998.

LOGAN, J. A. et al. Tropospheric chemistry: A global perspective. Journal of Geophysical Research, v. 86, n. C8, p. 7210, 1981.

LONGO, K. M. et al. The coupled aerosol and tracer transport model to the brazilian developments on the regional atmospheric modeling system (cattbrams)-part 2: Model sensitivity to the biomass burning inventories. Atmospheric Chemistry and Physics, v. 10, n. 13, p. 5785-5795, 2010.

MARENGO, J. A. et al. Hydro-climatic and ecological behaviour of the drought of Amazonia in 2005. Philosophical Transactions of the Royal Society B-Biological Sciences, v. 363, p. 1773-1778, 2008.

MATA, L. J. et al. Working Group II: Impacts, Adaptation and Vulnerability Latin America. [s.l: s.n.].

MORAES, B. C. DE et al. Variação espacial e temporal da precipitação no Estado do Pará . Acta Amazonica, v. 35, n. 2, p. 207-214, 2005.

MORTON, D. C. et al. Cropland expansion changes deforestation dynamics in the southern Brazilian Amazon. Proceedings of the National Academy of Sciences, v. 103, n. 39, p. 14637-14641, 2006.

REGALADO, J. et al. The Effect of Biomass Burning on Respiratory Symptoms and Lung Function in Rural Mexican Women. American Journal of Respiratory and Critical Care Medicine, v. 174, n. 8, p. 901-905, 15 out. 2006.

SANTOS, F. C. et al. Biomass burning emissions disturbances on the isoprene oxidation in a tropical forest. Atmospheric Chemistry and Physics Discussions, p. $1-35,2017$.

SEINFELD, J. H.; PANDIS, S. N. Atmospheric Chemistry and Physics: From Air Pollution to Climate Change. 3rd Editio ed. New York: John Wiley \& Sons Ltd, 2016.

SHINE, K. P. et al. Radiative forcing of climate. In: HOUGHTON, J. T.; JENKINS, G. J.; EPHRAUMS, J. J. (Eds.). . Climate Change: The IPCC Scientific Assessment. Cambridge: Cambridge University Press, 1990. p. 365.

SIGSGAARD, T. et al. Health impacts of anthropogenic biomass burning in the developed world. The European Respiratory Journal, v. 46, n. 6, p. 1577-88, 24 dez. 2015.

SOARES NETO, T. G. et al. Laboratory evaluation of Amazon forest biomass burning emissions. Atmospheric Environment, 2011. 
VERÍSSIMO, A. et al. Priority Areas for Establishing National Forests in the Brazilian Amazon. Conservation Ecology, v. 6, n. 1, p. art4, 14 fev. 2002.

WEICHENTHAL, $S$. et al. Biomass Burning as a Source of Ambient Fine Particulate Air Pollution and Acute Myocardial Infarction. Epidemiology (Cambridge, Mass.), v. 28, n. 3, p. 329-337, 2017. 